\title{
Aníbal Quijano e a racionalidade alternativa na América Latina: diálogos com Mariátegui
}

\author{
DENI ALFARO RUBBO ${ }^{I}$
}

A interpretação da nossa realidade a partir de esquemas alheios só contribuiu para tornar-nos cada vez mais desconhecidos, cada vez menos livres, cada vez mais solitários. [...] A América Latina não quer e nem tem porque ser um peão sem rumo ou decisão, nem tem nada de quimérico para que seus desígnios de independência e originalidade se convertam em uma aspiração ocidental.

(Gabriel García Márquez, 2011, p.26)

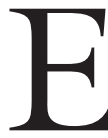

STE ARTIGO tem como objetivo discutir, ainda que de uma maneira preliminar, a perspectiva "decolonial” de Aníbal Quijano (1930-2018) e seus usos a partir de José Carlos Mariátegui. Em primeiro lugar, relacionamos o contexto histórico latino-americano desde a década de 1980 ao esforço de interpretação de Mariátegui por Aníbal Quijano, balizado, sobretudo, pela formulação de uma teoria fundacional (filosófica, epistemológica, ética e política) sobre a especificidade da América Latina. Na sequência, Quijano redescobre, assim, certo Mariátegui associado à renovação crítica da teoria social latino-americana. Através de múltiplos mecanismos de difusão, ele estabelece uma reconhecida caracterização filosófica e epistemológica do arsenal mariateguiano, visto como bastião da crítica eurocêntrica ("racionalidade alternativa"), para legitimá-lo como referência fundamental da teoria da "colonialidade do poder".

\section{A recepção de Mariátegui em Aníbal Quijano}

Falecido em maio de 2018, o cientista social peruano Aníbal Quijano alcançou alto prestígio e reputação acadêmica indiscutíveis nas ciências sociais, não somente em seu país de origem, como também por toda a América Latina. ${ }^{1}$ Suas trajetória e obra também despertam a curiosidade de pesquisadores de outras regiões, vinculados particularmente ao campo dos assim chamados "estudos pós-coloniais”. Professor da Faculdad de Ciencias Sociales da Universidad Nacional Mayor de San Marcos (UNMSM) na capital peruana desde 1964, com passagem pelo Departamento de Sociologia da Binghamton University (New York $)^{2}$ a convite do sociólogo Immanuel Wallerstein, Quijano ainda foi pesquisador visitante de inúmeras universidades latino-americanas (Chile, Bolívia, México e Venezuela). No Brasil, foi docente no Instituto de Estudos Avançados na Universidade de São Paulo (IEA-USP) entre 1992-1993.³ 
Esse reconhecimento crescente deve-se, em grande medida, a mais de meio século de fecunda produção intelectual, fruto do desenvolvimento de repertórios conceituais inovadores e de diversos campos temáticos nas ciências sociais da América Latina. ${ }^{4}$ A originalidade intelectual da "sociologia crítica" desenvolvida por Quijano e seu compromisso político serão também, como destaca Villena Fiengo (2016, p.4), "um componente fundamental do ethos sociológico latino-americano".

De todo modo, as homenagens ao vigor de sua obra recaem principalmente sobre sua produção a partir da década de 1990. Nesse período delineia-se, pouco a pouco, a ambiciosa formulação de uma teoria filosófica, epistemológica, ética e política fundacional sobre a especificidade da América Latina. Demarca-se, então, a perspectiva da "colonialidade de poder". Introduzido por Quijano, o neologismo transformado em conceito-chave faz referência a uma estrutura de poder particular do domínio colonial à qual foram submetidas as populações nativas a partir de 1492, e que ainda persiste após a independência (cf. Quijano, 1992, p.12). A colonialidade seria a outra face da modernidade, seu lado negativo, obscuro. Raça, gênero e trabalho foram as três instâncias de classificação, ao mesmo tempo, constituintes do capitalismo mundial moderno/colonial (Quijano, 2000, p.343).

Essa perspectiva transformou-se em um eixo temático obrigatório nas ciências sociais da América Latina. Rita Laura Segato (2014, p.12), estudiosa do feminismo no continente, afirma categoricamente que a perspectiva crítica de Aníbal Quijano representa um "momento de ruptura (ou, ainda, um 'giro copernicano') no campo das ciências humanas no continente e uma nova inspiração para reorientação dos movimentos sociais e luta política".${ }^{5}$ Walter Mignolo, um dos integrantes do extinto Latin American Subaltern Studies Group e membro do "Grupo Modernidade/Colonialidade" (integrado por Quijano), ${ }^{6}$ declarou seu êxtase ao conhecer um dos ensaios do autor sobre o lado obscuro da modernidade ocidental.

Logo depois estive em Bogotá e achei outro livro recém-publicado: Los conquistados: 1492 y la población indígena de las Américas, editado por Heraclio Bonilla. O último capítulo desse livro chamou a minha atenção. Era de Aníbal Quijano, de quem eu já tinha ouvido falar, mas que não me era familiar. O ensaio, também posteriormente publicado no Cultural Studies, intitulou-se "Coloniality and modernity/rationality". Peguei o livro, fui tomar outro café e devorei o ensaio, cuja leitura foi uma espécie de epifania. (Mignolo, 2017, p.2)

Mignolo (2014, p.6) ainda reconhece que uma das inspirações da construção do conceito de colonialidade vem de José Carlos Mariátegui, que construiu analiticamente relações entre raça, terra e colonialismo. De fato, Aníbal Quijano possui uma relação profunda com a obra mariateguiana, sendo provavelmente o sociólogo da América Latina que mais se aproximou dela. ${ }^{7}$ Contudo, as intervenções de Quijano acerca do autor de Siete ensayos de interpretación de la realidad peruana têm pouca representatividade diante do conjunto hetero- 
gêneo de sua obra, que lhe tem garantido consagração acadêmica e traduções para diversos idiomas. "Textos menores" que foram registrados por meio de organizações de edições, prólogos de livros, simpósios, conferências, entrevistas, debates, publicações em revistas etc. No entanto, são justamente esses "pequenos frascos" que podem apontar delineamentos do conjunto da obra do autor e, consequentemente, de sua resposta teórica frente à estrutura do sistema mundo capitalista moderno/colonial. Iluminam, mais do que qualquer outro tema explorado pelo autor, as complexas relações entre marxismo, crise da modernidade e América Latina.

Além disso, a obra mariateguiana na sociologia de Quijano passa por apropriações diferentes de acordo com o momento da trajetória intelectual e política adotada pelo autor. Quijano não "fala" por Mariátegui, postura adotada por certos "especialistas" e "políticos"; não procura justificar as escolhas teóricas e políticas do autor, ou restringir-se apenas a transcrever a argumentação mariateguiana. Adota uma postura ousada, não isenta de contradições, que "violenta" Mariátegui. Ora, não foi assim que Mariátegui fez com autores como Marx e Sorel? Como bem afirma o historiador Flores Galindo (1994, p.437), Mariátegui "utilizou Marx no sentido mais egoísta da palavra, o empregou como instrumento, sem nunca temer a heresia ou infringir alguma regra".

\section{Reencontro e debate: Mariátegui, para quê?}

O início da trajetória acadêmica de Quijano coincide com a efervescência dos debates acerca da Teoria da Dependência. Nas décadas de 1960 e 1970, "época de ouro" das ciências sociais da América Latina, Quijano procurou analisar a especificidade socioeconômica, política e cultural do Peru. Tal como Mariátegui já indicava na década de 1920, o Peru não poderia ser tratado como objeto de análise isolado, como se fosse condenado a seguir o modelo europeu. Aos olhos de Quijano, fazia-se necessária uma alternativa à análise de crivo evolucionista e às análises estrutural-funcionalistas. De fato, ao mover-se "dentro da órbita da civilização ocidental" (cf. Mariátegui, 1970a), o país tecia relações com o sistema capitalista internacional, mas dentro de uma simultaneidade de tempos históricos marcada pelo encontro entre tradições andinas e a modernidade europeia. Assim, a busca pela especificidade, unindo marxismo e investigação da realidade nacional, teria por resultado o enfraquecimento da perspectiva eurocêntrica nas ciências sociais e no âmbito das estratégias políticas. ${ }^{8}$

A década de 1980 seria decisiva para uma mudança de perspectiva de Aníbal Quijano nas décadas subsequentes. Fundamentalmente, uma profunda reavaliação de suas orientações teóricas que até ali vigoravam fortemente em sua formação intelectual. Ele passa a problematizar de maneira mais incisiva algumas ferramentas de análise por ele utilizadas, em especial o marxismo, e o próprio eixo temático de sua pesquisa sofre mudanças substantivas.

Era um contexto de cambios e de crise nas ciências sociais em geral. Em algumas ocasiões, Quijano lamentou que a produção latino-americana contempo- 
rânea atendesse a necessidades puramente "tecnocráticas" (como teria colocado Wright Mills, um "abstracted empiricism"), e se distanciasse de uma perspectiva de análise de conjunto e, por meio dela, dos padrões de poder atuante. O declínio da "teoria da dependência" na década de 1980, um dos pontos mais criativos da história das ciências sociais e do marxismo na América Latina, confirmaria essa tendência (cf. Beigel, 2006). Evidentemente, essa crise tinha relação com fatores externos ao campo intelectual: crise mundial do capitalismo de 1973, queda do Muro de Berlim em 1989 e, nos anos seguintes, a percepção de uma hegemonia mundial estadunidense. Na cena peruana, o fracasso da Izquierda Unida (IU) e a ascensão e queda do Sendero Luminoso.

Reforça essa transição o trabalho "La tensión del pensamiento latinoamericano", apresentado em 1986 por Quijano no Colóquio Internacional "Marx, para quêe?" da Sociedade Portorriquenha de Filosofia (Quijano, 2014a, p.697704). Na realidade, o título da comunicação de Quijano poderia ser uma paródia do título do próprio colóquio: Mariátegui, para quê? Com efeito, Marx é pouquíssimo trabalhado no texto de apresentação, já que para o autor é premente expressar considerações sobre a produção de conhecimento na América Latina por meio da figura de Mariátegui.

Não analisaremos aqui o vínculo que Quijano estabeleceu com a obra de Mariátegui durante as décadas anteriores à de 1980. Isso exigiria o exame de dois contextos distintos da trajetória intelectual quijaniana, cada qual com proporções e graus de importância distintos. Em primeiro lugar, a organização, ao lado de Manuel Scorza (1956), de uma antologia sobre Mariátegui, em um momento de difusão precária da obra mariateguiana, de disputas políticas na esquerda peruana e início da crise do stalinismo. Em segundo lugar, Quijano publica em 1979 um extenso prólogo (cf. Quijano, 1981) para a edição venezuelana de Siete ensayos de interpretación de la realidad peruana - o prólogo transformou-se em livro independente e foi publicado no Peru e no México - a pedido da Biblioteca Ayacucho que tinha o intuito de introduzir o leitor na fortuna do Amauta dentro de um contexto de "redescoberta". Nessa época em que Quijano incorpora e difunde Mariátegui, estava envolvido com a edição da revista Sociedad y Política (1972-1983) e o Movimiento Revolucionário Socialista (MRS).9

Por outro lado, é um intuito bastante diverso que anima o trabalho de Quijano apresentado em abril de 1986. O ponto nevrálgico dessa comunicação já pressupõe uma profunda reformulação não apenas do debate sobre Mariátegui, como também das ciências sociais e do marxismo na América Latina. Embora esse texto seja relativamente breve, é possível afirmar, portanto, que sua proposta é audaciosa e nele se reflete a produção posterior de Quijano.

O autor inicia seu diagnóstico com a seguinte ironia: a produção de Mariátegui em seus últimos anos tem volume menor do que a de pouco mais de meio século de estudos mariateguianos. As motivações para esse balanço quantitativo não são apenas negativas. Seja pela complexidade e qualidade dos estudos 
nascentes, seja pela "enorme aptidão" dos estudos mariateguianos para "admitir leituras novas, o tempo todo, sempre que existe uma 'curva importante na história da América Latina", essa vocação para a novidade parece fazer com que a obra do Amauta seja, atualmente, "um território cada vez mais concorrido" (Quijano, 2014a, p.697, grifo nosso).

Em seguida, Quijano retorna ao velho debate sobre a tensão entre pensamento marxista e não marxista na trajetória intelectual de Mariátegui. Sua impressão é a de que o imbróglio acerca do ponto de vista mariateguiano do conhecimento seja, na realidade, expressão de um problema crônico na história do pensamento latino-americano.

Na minha opinião, com Mariátegui estava constituindo-se pela primeira vez, de maneira explícita, um campo original que não se esgota no modo eurocentrista de admissão e produção do movimento marxista de conhecimento, nem, do outro lado, o movimento de reflexão chamado de conhecimento idealista. Esse campo cultural original implica que o logos e o mito não sejam, não podem ser externos entre si, senão contraditórios em um mesmo movimento intelectual, no qual a imaginação atua com e através da análise lógica para constituir o conhecimento como representação global ou globalizante e no movimento, que é indispensável para outorgar status suprahistórico, mítico. (ibidem, p.700)

Esse campo cultural inaugurado por Mariátegui exporia a originalidade de seus descobrimentos. A tensão entre marxismo e filosofia da história, o primeiro como aposta no conhecimento da realidade nacional e a segunda baseada na religiosidade e metafísica, não estaria assentada em uma dualidade intransponível, mas, sim, em uma superação não isenta de tensões. Os embriões de uma nova história estariam no cruzamento entre um tempo profano e um tempo mítico. Especialmente este último é ressaltado por Quijano nos seguintes termos:

Porque é real, ainda que inefável, tal como a história pode ser captada na realidade como tempo mítico para mostrar todo seu sentido. E onde, portanto, a história é uma aposta, no mais pascaliano dos sentidos, não há como conhecer e penetrar a realidade, não há como representá-la em sua totalidade, em seu movimento, em sua transfiguração incessante. Não há como transformá-la e transfigurá-la colocando tudo isso somente no tubo europeu, eurocentrista, no qual tanto o marxismo como o que não é marxista têm de mover-se até hoje na América Latina. (ibidem)

Esses excertos são expressão de um momento importante na trajetória intelectual de Quijano. A partir de meados da década de 1980, o autor aprofunda seu acerto de contas definitivo com as tradições teóricas "eurocêntricas" (marxistas e não marxistas), que jamais admitiriam uma junção entre essas duas temporalidades. Na acepção eurocêntrica, por um lado, a oposição entre logos e mito exclui ambos os termos; em compensação, na perspectiva não eurocêntrica formulada por Quijano, ela atua como integrante de um mesmo movimento de consciência e de reflexão. Mais do que isso, esse teria sido o "grande dilema”, o 
ser ou não ser da história do pensamento latino-americano acossado pelas perspectivas eurocêntricas que influenciam, segundo o autor, as formações históricas de extração colonial.

\section{Literatura e "simultaneidade dos tempos"}

Qual será o recurso utilizado por Quijano para explicar os significados do "tempo mítico"? Ele recupera um capital cultural adquirido em sua formação desde a juventude, mas que poucas vezes utilizou explicitamente em seus estudos sociológicos e políticos posteriores: a literatura latino-americana. Refere-se particularmente àquela vertente que combina o fantástico e o real, refletindo a vida social e os conflitos do continente. Desse modo, essa combinação transcenderia as delimitações do sistema literário: "Não é verdade que o real maravilhoso, ou o realismo mágico, somente tenha implicações estritamente literárias, mas também tem algo a dizer sobre o conhecimento e a compreensão da realidade histórica da América Latina" (Quijano, 2014a, p.700-1).

Não custa recordar que na época de Mariátegui, apesar do mundo indígena, dos espaços rurais e do "analfabetismo", a literatura era porta de entrada para se discutir o país como nação. Não por acaso, "Processo de literatura" é o mais extenso dentre todos os Siete ensayos. Flores Galindo recorda-se de uma conversa no Simpósio "Literatura y Identidad Nacional en el Perú", em agosto de 1988, na cidade de Jauja, em que Quijano e Antonio Cornejo (um dos críticos literários mais afamados do Peru) justificavam o protagonismo da literatura não apenas em Mariátegui, mas para sua própria geração - isso sem mencionar que Mariátegui planejou escrever um romance sobre o Peru em sua fase "madura". Aos olhos dos três intelectuais, o uso de instrumentos racionais enquadrados por conceitos rígidos parecia limitado em um país cujas tradições culturais e tempos históricos são distintos dos da tradição do Ocidente (Flores Galindo, [1988] 2007, p.283-4).

A admiração do sociólogo peruano pelos contemporâneos latino-americanos, como o mexicano Juan Rulfo, o argentino Jorge Luis Borges e o colombiano Gabriel García Márquez (que havia recém-ganhado o Prêmio Nobel de Literatura de 1982) consistia em enxergá-los como desbravadores do enigma dos "tempos simultâneos" da América Latina, sob a mediação do "estético-mítico", cujo resultado seria mais satisfatório do que aquele alcançado pelos trabalhos sociológicos. Aos olhos de Quijano, trata-se de uma linhagem de autores que procuram desvendar o conflito de identidade do continente latino-americano. Especialmente, o andino José Maria Arguedas (1911-1969) parece fasciná-lo, não apenas por ser seu conterrâneo e por terem estabelecido laços de amizade (Forgues, 1993, p.297-8), mas pela intensidade das narrativas de Arguedas, construídas com "linguagem transgressora", situadas no universo periférico andino e em meio às suas mitologias.

Escritor, folclorista, tradutor, poeta, etnógrafo e docente universitário, Arguedas foi provavelmente o intelectual de maior prestígio do Peru na década 
de 1960. Ao longo de sua trajetória, o autor de Os rios profundos laborou pelo resgate e inserção da cultura regional andina quéchua - sua língua, arte e cultura - no mapa da nacionalidade peruana, o que resultou num especial cruzamento entre literatura e antropologia. Curiosamente, Arguedas (2016, p.294) foi um leitor ávido da revista Amanta, e compartilhava das ideias socialistas propagadas por Mariátegui. Assim, Quijano reconhece uma dupla articulação na obra arguediana: a subversão da estrutura narrativa, ao incorporar a oralidade andina (a quéchua, em particular) à língua espanhola dominante, e um projeto cultural de longo prazo, como aposta sobre o sentido da história, que ao mesmo tempo o transcende e transfigura. A utopia arguediana como programa de "subversão linguística" tinha como meta expressar as necessidades de transmissão dos dominados e o projeto global de reconstituição do sentido histórico da sociedade peruana (Quijano, 2014b, p.693).

Esse exercício de "transculturação narrativa" na obra de Arguedas, segundo a expressão de Ángel Rama, consiste na tradução da cultura local no sistema global. Em última análise, trata-se de junções (e subversões) dos elementos que o eurocentrismo formalizou e categorizou como necessariamente opostos (logos versus mito; ciência versus fé; razão versus emoção). Para Quijano (2014a, p.701), trata-se de "admitir a cultura ocidental como dominante sob condição de que nela possam caber todas as possibilidades de expressão e criatividade do que não era ocidental. Na realidade, é comer as entranhas do dominante para incorporá-lo àquele que é, até aquele momento, dominado. E convertê-lo em alternativa não excludente, pelo contrário, envolve o conjunto da história desse movimento".

Ao adotar essa perspectiva antropofágica - que não reconhece a literatura brasileira em seu repertório -, essa vertente da literatura latino-americana descobre, segundo Quijano, um espaço cultural sui generis na América Latina, "e creio que para a possibilidade de reconhecimento da realidade histórica latino-americana, de sua historicidade especial" (ibidem). Ou seja, uma colocação no terreno da epistemologia e metodologia que leva em conta não apenas diferentes conhecimentos sobre a sociedade, como também modos diferentes de conhecê-la.

Assim, aos olhos de Quijano, Mariátegui seria o arquiteto da América Latina, que reúne temporalidades distintas daquelas da cultura europeia-ocidental.

Eu creio que isso seja possível a partir de Mariátegui. Não que Mariátegui estivera tentando formalmente isso. Não estou seguro de que ele fora consciente de que estava implicando um movimento de reflexão. Quando ele estava tratando de sustentar que o processo de classes na América Latina poderia conduzir a uma revolução, não porque a ciência propunha assim, mas porque o mito da revolução socialista era capaz de mover a fé das multidões nessa direção, na minha opinião, ele não estava somente apelando formalmente a Marx e Sorel. Isto é, ao que estava no primeiro plano em sua consciência. (Quijano, 2014a, p.702) 
Se outrora a crítica da herança eurocêntrica existia de maneira mais ou menos subterrânea no itinerário de Quijano, há, a partir do texto "La tensión del pensamiento latinoamericano", uma indiscutível atenção ao problema do eurocentrismo. Com efeito, trata-se do ponto de partida de indagações persistentes que sustentam a perspectiva epistemológico-metodológica adotada pelo pensador latino-americano na fase de sua mais reconhecida produção intelectual.

\section{A “agonia” pela descolonização epistemológica}

Nessas "circunstâncias históricas muito especiais" de desmanche de sociedades burocráticas, ascensão do capitalismo neoliberal e crise categorial do conhecimento, Quijano persegue uma forma de conhecimento dotada de uma tarefa central: a "descolonização epistemológica" como crítica explícita do evolucionismo unilinear e unidimensional do eurocentrismo.

O eurocentrismo não consiste, pois, na localização geográfica do observador. Se fosse assim, deveríamos ter um latinoamericacentrismo, um africacentrismo, etc. etc., e o eurocentrismo não seria realmente um problema. Tampouco se coloca como uma questão de autonomia intelectual diante da imposição europeia, que algum nacionalismo intelectual ou cultural pudesse resolver. A descolonização da epistemologia não implica sua nacionalização. E embora geralmente se manifeste como etnocentrismo e, sem dúvida, o implique, também não seria pertinente admitir que esse traço seja a marca básica de identificação do eurocentrismo. (Quijano, 1994, p.XII)

Em 1991, Quijano publica um trabalho inteiramente dedicado a José Carlos Mariátegui: textos básicos. Trata-se de uma seleção de quarenta e cinco textos separados por notas introdutórias para cada seção. Como uma grande e difundida contribuição sobre Mariátegui já havia sido realizada com a introdução de 1979, o prólogo redigido no verão de 1991 podia ter outras ambições. Por um lado, seria vão sugerir que o conjunto dos textos escolhidos tivesse a pretensão de responder às preferências ideológicas do organizador. Por outro, seria demasiado ingênuo supor que um cientista social do perfil de Quijano não estabelecesse critérios que colocassem a antologia em sintonia com a perspectiva de "descolonização epistemológica", que se tornava cada vez mais clara. Tanto é que não apenas o prólogo em questão, mas também o restante dos textos produzidos sobre Mariátegui são acompanhados por linhas argumentativas, hipóteses e problemas que se complementam. À medida que Quijano explora diferentes dimensões da obra mariateguiana, é possível, portanto, entrever a unidade de um interesse coerente e unificado.

Para Quijano, não há dúvida de que o autor de La escena contemporánea elaborara questões novas e modos diferentes de indagar a especificidade histórica da América Latina. Mariátegui elabora uma perspectiva cognitiva capaz de produzir conhecimento diverso daquele que resulta da racionalidade instrumental ocidental. Com efeito, encontrar-se-ia em sua obra e trajetória a possibilidade de repensar o dispositivo do conhecimento que tem permitido a dominação europeia, bem como o esforço de liberar a teoria social da dominação de categorias 
produzidas pela colonialidade do poder. Ou seja, Mariátegui criaria uma relação epistemológica original com o mundo. Resistente à racionalidade reducionista e tecnocrática eurocêntrica, principalmente às versões associadas às burocracias socialistas, o arsenal mariateguiano, chamado de "crítica revolucionária peruana", também abriria um flanco analítico para uma nova concepção da história latino-americana. Desse modo, ao atribuir à obra de Mariátegui o papel de invenção de uma nova maneira de conhecer, Quijano promove o autor à condição de filósofo que traz proveito para seu novo empreendimento teórico. Não por coincidência, "racionalidade alternativa" é o termo amiúde utilizado por Quijano não só para caracterizar o pensamento de Mariátegui, como também para nomear seu próprio projeto da "colonialidade/des-colonialidade de poder". ${ }^{10}$

Evidentemente, a proposta de uma "racionalidade alternativa" mariateguiana seria implícita e, muitas vezes, intuitiva, já que não teria sido desenvolvida de maneira consciente e sistemática. Não há, em Mariátegui, um sistema filosófico coerente e imutável - ou uma "teoria integral". Na realidade, toda sua reflexão tomou forma de ensaio no campo da produção jornalística. Portanto, qualquer tentativa de sistematização de seu pensamento é sempre incerta e controvertida.

Quijano tinha ciência desse componente sui generis da produção de Mariátegui. Isso posto, é possível afirmar que sua leitura não cria mais um fetiche em torno de Mariátegui filósofo. Por se tratar de um pensamento crítico como o de Quijano, nada impede de antemão que se sustente a existência de uma reflexão filosófica mariateguiana e se afirme a necessidade de resgatá-la. Afinal, não foi apenas como homem de ação, mas fundamentalmente no âmbito intelectual que Mariátegui deixou contribuições decisivas para a cultura política peruana. São bem conhecidos Defensa del marxismo e El alma matinal y otras estaciones del hombre de hoy (Mariátegui, 1959; 1970b), livros organizados pelo autor mas publicados postumamente, nos quais se verifica a exaltação da ação heroica individual e social na história, bem como o acento sobre a dimensão ética do socialismo em contraposição ao evolucionismo e ao positivismo na história.

Quijano aponta ainda o exercício constante de "autonomia intelectual", principalmente no debate marxista de seu tempo, dentro e fora da América Latina. Diga-se de passagem, essa característica põe em relevo uma prática de autonomia intelectual mariateguiana que soube articular o problema global do conhecimento com a questão da revolução. Esses dois elementos, inseparáveis de um mesmo movimento, parecem intrigar Quijano:

Na minha opinião, o que segue chamando realmente atenção em JCM e me parece às vezes difícil de ver como foi alcançado é o modo como procura levantar simultaneamente as questões centrais de um exercício político chamado revoluçã 0 ; em seus próprios termos, ao mesmo tempo [procura levantar] os problemas do modo de produzir conhecimento, do modo de produzir cultura, isto é, do modo de subverter não somente as relações sociais materiais, como também as relações sociais intersubjetivas no mesmo movimento. (Quijano, Gutiérrez, López, 1994, p.41, grifo do autor) 
Tendo em vista essa simultaneidade de projetos, seria complicado classificar Mariátegui dentro de alguma vertente teórica: crítico da sequência histórica europeia como universalidade, adversário marxista da ideologia do "progresso", religioso partidário do materialismo, nostálgico das formas comunitárias indígenas do passado etc. Não sem razão, a propósito desse pensamento extremamente singular, o único personagem com que Quijano traça comparação é outro outsider da história intelectual do século XX: o filósofo alemão Walter Benjamin.

[...] o processo de reflexão mariateguiana pode ser melhor relacionado com Walter Benjamin, não somente por essa peculiar tensão de uma racionalidade que nega o reducionismo, mas também porque em ambos a revolução é pensada como uma questão de redenção, sem que isso desemboque, no entanto, em um território estranho à própria história. Desse modo, em ambos, a materialização da igualdade social, solidariedade, da reciprocidade, do amor ao próximo, na vida cotidiana da sociedade, não se refere a - nem depende de - nenhum poder religioso institucional. Em Benjamin se move uma densa corrente que leva desde as fontes da Cabala até a história filosófica europeia. De que bebia a desaforada sede mariateguiana? Essa é ainda uma interrogação aberta. (Quijano, 1991, p.X)

\section{"A heresia é indispensável para comprovar a saúde do dogma"}

Sobretudo, uma questão precípua na interpretação de Quijano sobre Mariátegui é o lugar que ocupa o marxismo. Para ele, a primeira confrontação entre "materialismo histórico" e a teoria marxista da história (Quijano, 1990) na América Latina deu-se por meio das posições mariateguianas na Primeira Conferência Comunista Latino-americana, reunida em Buenos Aires, ocorrida em 1929. Tratava-se da versão eurocentrista hegemônica defendida pelo Secretariado Latino-Americano e a apresentação dos trabalhos de Mariátegui ("Punto de vista Antimperialista" e "El problema de las razas en America Latina") (Mariátegui, 1969). ${ }^{11} \mathrm{Nem}$ mesmo toda manifestação de apoio político ao bolchevismo e as inúmeras declarações sobre Lenin como o mais importante continuador de Marx esmaeceram os dissensos teóricos e políticos em torno das propostas aventadas por Mariátegui. Mesmo com esse parentesco teórico irredutível com a teoria materialista da história, a denominação "marxismo de Mariátegui" ocasiona desconforto para Quijano. Ela não seria apenas diferente e distante da produção do "materialismo histórico", mas, na verdade, a ele dirige-se decididamente em sentido oposto. Por isso, conclui Quijano (1995, p.69), "chamar Mariátegui simplesmente de marxista é recorrer a um nome que se pode aplicar para todos os marxismos e, dessa maneira, a ninguém, sem explicar em que consiste sua especificidade".

Um trabalho que chamou a atenção do sociólogo peruano foi Mariátegui o la experiencia del otro, de Osvaldo Fernández Díaz (1994), publicado dentro do contexto de comemoração do centenário do nascimento de Mariátegui. Um dos pioneiros na divulgação de Gramsci no Chile e professor de Filosofia da Universidade de Valparaíso, o trabalho apresentado por Fernández Díaz consis- 
tia em uma hermenêutica de Defensa del marxismo, especialmente do capítulo sobre a polêmica com o belga Henri De Man.

Para o intelectual chileno, além das respostas às objeções do belga em Au-delà du marxisme [Para além do marxismo], o texto de Mariátegui não teria como objetivo expressar meramente uma proclamação da fé revolucionária, tampouco trazer para o debate aportes sobre o método científico, mas sim interrogar o próprio instrumento utilizado: o marxismo. Por meio de uma análise talmúdica, palavra por palavra, Fernández Díaz acompanha o uso dos conceitos, os recursos estilísticos (metafóricos) e o percurso da argumentação do Amauta. Um momento particular dessa minuciosa leitura é a incursão histórica no interior do "revisionismo" mariateguiano. Embora o termo tenha uma conotação puramente negativa para a ortodoxia marxista da II Internacional, Mariátegui procuraria "transformar a palavra em conceito" para liberá-la da rigidez imposta e pô-la em operação, já que seu significado oficial não o apetecia. O "revisionismo" estaria assentado em "uma história adjunta, lateral, conflitiva, mas que não tem existência independente, e cuja explicação definitiva somente pode ser lida na mesma história da qual se separa" (Fernández Díaz, 1994, p.123). De acordo com o autor, o exemplo mais interessante e enigmático da revisão do "revisionismo" é a oposição entre heresia e dogma centrada em uma colocação sui generis de Mariátegui: "a heresia é indispensável para comprovar a saúde do dogma".

Na leitura do filósofo chileno, quando postula uma relação de necessidade entre heresia e dogma, Mariátegui "produz um choque, um contraste semântico, que ilumina de maneira diferente o problema do revisionismo, criando um ponto de vista alternativo" (Fernández Díaz, 1994, p.125). O nexo entre heresia e dogma é mediado pela noção de "saúde"; a heresia é momento necessário do dogma, um vigilante que cumpre o papel de comprovação. "Se passarmos a ler o que está sendo aludido, poderemos concluir que a afirmação representa a consagração do revisionismo como momento necessário do marxismo" (ibidem). A presença do fator herético cumpre uma função "reativa", interna e necessária, "estimula a atividade intelectual" e "provoca uma reação" no corpo central do dogma. Dessa forma, por meio da experiência do outro, Mariátegui transformaria a heterodoxia (fala-se também em "militantes heterodoxos") em um momento necessário e interno à ortodoxia, esta mantenedora dos conceitos puros e das antinomias da Razão.

Essa criativa interpretação do filósofo chileno teve efeito positivo nas lentes de Quijano. Não por coincidência, ele redigirá o prólogo do livro de Fernández Díaz declarando seu entusiasmo com a exegese de Defensa del marxismo. Nas palavras do sociólogo peruano: "Não conheço outro trabalho que tenha se destacado com tanta perspicácia para descobrir e mostrar a delicada associação entre ética e epistemologia que Mariátegui tinha logrado revelar" (Quijano, 1994, p.XV). Amauta vigilante solitário das ortodoxias constituídas, questiona- 
dor dos preceitos oficiais: essa parece, portanto, a imagem apropriada aos olhos de Quijano. Por conseguinte, no pensamento de Mariátegui, não se trata apenas de uma filiação e de uma fé, mas de uma "racionalidade integradora".

$\mathrm{Na}$ confluência entre o marxismo crítico latino-americano e a perspectiva da descolonização epistemológica, a contribuição mais original de Mariátegui, segundo Quijano, é sua proposta formulada no primeiro capítulo do Siete ensayos ("Esquema de la evolución económica"). Mariátegui entende que a formação histórico-social peruana ancora-se em uma estrutura global de elementos desiguais, contraditórios e combinados. Eis a originalidade histórica e teórica da experiência latino-americana: "feudalismo" (ou "semifeudalidade"), "servidão" e "capitalismo" não constituem modos de produção separados atuando em um mesmo território. Na realidade, se articulam em uma mesma estrutura de poder (ou numa "totalidade heterogênea") sob o domínio do capitalismo, embora o capitalismo não seja o único padrão estrutural da totalidade social da América Latina. Portanto, distintos modos de produção articulam-se entre si de maneira coetânea, complementar e contraditória. Quijano designa essa análise como "heterogeneidade histórico-estrutural". Originalmente, o termo foi elaborado como alternativa ao "dualismo", que era a pedra angular da teoria da "modernização". Desse modo, nessa formulação mariateguiana encontra-se uma afinidade eletiva entre a vertente da teoria marxista da dependência e a proposta da "colonialidade do poder":

A ideia de semifeudalidade é uma afirmação de JCM, mas é tirada de uma proposta de conhecer uma totalidade que não é nem sistemática nem orgânica. São dois modos dominantes de constituir a ideia de totalidade no Ocidente. Em JCM, trata-se de uma totalidade que se constitui com a heterogeneidade histórico-estrutural. Esta é uma fórmula latino-americana dos anos 1960, mas é exatamente o que está se elaborando implicitamente em JCM nos anos 1920. Demoramos quarenta anos para reencontrá-la na América Latina, de um lado na luta contra o positivismo, o evolucionismo, a teoria da modernização e, de outro lado, contra o modo de produção. (Quijano; Gutiérrez; López, 1994, p.44)

De qualquer forma, Quijano reconhece que os aportes mariateguianos sejam, em essência, antieurocêntricos. Contudo, justamente por não concluir o empreendimento de uma racionalidade alternativa, Mariátegui teria limites impostos pelas condições históricas e específicas da experiência latino-americana da década de 1920. Na concepção de Quijano, ele não estaria livre das influências europeias do debate do "materialismo histórico" centro-europeu durante o manejo de conceitos como "feudalismo", "capitalismo" e "comunismo", ainda que fizesse uso radicalmente diferente do predominante. Há também a proposta mariateguiana de "socialismo indoamericano" (terminologia que já havia sido estabelecida por Haya de la Torre sobre o indoamericanismo) apresentada no famoso editorial da revista Amauta "Aniversarie y balanço" de 1928. Aos olhos de Quijano, a ideia deveria ser plenamente reformulada, pois a opção pelo índio 
da América Latina não integrava outros setores sociais explorados e oprimidos nesse projeto emancipador, como o negro, muito por conta de explícitos preconceitos de Mariátegui. ${ }^{12}$

Ademais, "uma das intrigas não resolvidas no debate mariateguiano é seu peculiar emprego das categorias 'raça' e 'etnia', de um lado; e, de outro, o cordão umbilical que liga sua noção de 'raça' com suas ideias sobre a 'questão nacional'" (Quijano, 1993, p.181). Essa não é uma questão trivial nas preocupações de Quijano, pois este estabelece a classificação da população mundial mediante novas identidades, em particular a noção de raça ("índio", "branco", "negro" e "mestiço"), conceito resultante do processo de legitimação e naturalização das relações de dominação iniciado com a colonização da América Latina.

Mariátegui recusou a categoria "etnia" para debater a problemática dos "índios" na América Latina. Em contrapartida, para Quijano, o termo "raça" seria uma categoria fundamentalmente bidimensional no horizonte mariateguiano: uma noção de civilização e uma noção intimamente ligada ao fenótipo. Muitas vezes, Mariátegui é contrário à ideia de "inferioridade racial" biológica, mas, em certas passagens, admite uma possível inferioridade histórica das "raças" indígenas.

Mariátegui foi capaz de observar que o "problema indígena" não podia ser solucionado sem a liquidação do gamonalismo e da servidão. Ao mesmo tempo, também explicitou que as relações de poder entre "brancos", "índios", "negros" e "mestiços" não consistiam somente nas relações de exploração, nem se originavam nela, mas implicavam também fenômenos de outro caráter e de outra origem, como a ideia de "raça". Esse era o sentido necessário de sua comparação das relações entre dominantes e dominadores na China ou no Peru, com relação à questão nacional. (Quijano, 1993, p.185)

Sem dúvida, na visão de Quijano, por mais inventivo que Mariátegui fosse na apropriação dessas categorias, os pontos negativos seriam mais importantes de ser ressaltados, tanto a respeito "de uma realidade heterogênea e diversa em um discurso homogeneizador" quanto por não desenvolver a questão racial nas relações de poder e classificação na história da América Latina.

De qualquer forma, a heterogeneidade do lugar e da trajetória da escritura mariateguiana no debate marxista ganharia um surpreendente relevo aos olhos de Quijano, principalmente nas relações entre a materialidade e a intersubjetividade das relações sociais e históricas na realidade latino-americana: o socialismo libertário. Em Quijano, a associação à tradição libertária deve-se sobretudo à insistência mariateguiana sobre o papel da comunidade indígena no processo de uma revolução socialista no Peru e na América Latina, algo semelhante ao processo dos trabalhadores russos que procuraram realizar a revolução contra o czarismo. Por outro lado, a questão da democracia direta em Mariátegui não poderia ser debatida separadamente da denominação "indoamericano". Pilar na história-cultural andina, o comunitarismo-agrário, completamente oposto ao 
império da "razão instrumental", desponta como organização solidária e coletiva, na reciprocidade, como fundamento da solidariedade social e da democracia, e no trabalho coletivo alegre. É explícita a simpatia de Quijano pelas "formidáveis utopias do movimento anarquista" na América Latina.

\section{Aventuras periféricas: crítica do eurocentrismo na América Latina}

A interpretação da fórmula "racionalidade alternativa" não passou isenta de críticas entre os estudiosos da obra de Mariátegui. Em El marxismo de Mariátegui y su aplicación a los 7 ensayos, o filósofo peruano David Sobrevilla (2012) diverge destacando três pontos: a) a expressão "racionalidade alternativa" não estaria exposta em nenhum dos textos de Mariátegui, além do que o próprio Amauta teria elaborado críticas da "razão"; b) preocupação ausente em demonstrar os traços dessa nova racionalidade que Mariátegui supostamente buscara; e c) uma abordagem excessivamente teórica "para caracterizar o marxismo do revolucionário peruano" (Sobrevilla, 2012, p.82). No entanto, no prólogo do livro, o italiano Antonio Melis (2012), um dos estudiosos mais qualificados sobre Mariátegui, assevera que a hipótese formulada por Quijano é "fecunda e não arbitrária". Ainda segundo o crítico italiano, talvez o "excesso de filologismo" de Sobrevilla ocultaria a percepção da noção de "racionalidade alternativa". Afinal, "embora seja verdade que Mariátegui não emprega a fórmula 'racionalidade alternativa', pode-se deduzir legitimamente esse conceito de sua obra" (Melis, 2012, p.19).

Ao adicionar um novo texto à terceira edição venezuelana dos Sete ensaios, Quijano responde à crítica de Sobrevilla reconhecendo os limites de sua interpretação:

Tem razão Sobrevilla se afirma que em Mariátegui não se encontram esses termos, nem sinais explícitos de que se propõe a encontrar ou produzir qualquer racionalidade alternativa. E talvez também seja certo que esses não são os termos mais eficazes para dar conta dos momentos e zonas de rupturas da reflexão mariateguiana com o eurocentrismo dominante no "materialismo histórico", nem do ativo debate atual contra o eurocentrismo e pela reconstituição de modos diferentes de produção de subjetividade ou, mais geralmente, de um novo universo de subjetividades, de imaginário, de memória histórica, de conhecimento. Pois não se trata de encontrar uma racionalidade alternativa universal que substitua o eurocentrismo. (Quijano, 2007, p.CXXV)

Aos nossos olhos, o terceiro ponto levantado por Sobrevilla é legítimo, pois a leitura exclusivamente teórica sobre Mariátegui, de certo modo, suaviza aspectos de sua trajetória, especialmente as atividades políticas que o levaram a travar contato com as classes populares (líderes indígenas, estudantis e operários). Como exemplos disso, podemos sublinhar sua participação em congressos (o Terceiro Congresso Indígena), atividade docente (nas Universidades Populares González Prada), fundação e direção de revistas (Claridad, Labor e Aman- 
ta) e de organizações políticas e sindicais (Partido Socialista Peruano e Confederação Geral do Trabalho). Seriam essas atividades práticas "eurocêntricas"?

Fato é que o legado mariateguiano acompanhou Quijano ao longo de toda a sua trajetória, por meio de diversas atividades políticas, acadêmicas e editoriais, seja em sua fase marxista em diálogo com a teoria da dependência, seja na crítica radical ao eurocentrismo conhecida como "colonialidade do poder". Independentemente da postura teórica e das ênfases distintas que adotou em seu itinerário, preocupou-se efetivamente com a divulgação da obra mariateguiana, e permaneceu fiel à premissa de seu autor predileto: decifrar a especificidade histórica da América Latina utilizando-se de um arsenal rico, heterogêneo e crítico da modernidade capitalista.

Ainda existe, evidentemente, uma diferença significativa entre as épocas de ambos os autores: no intervalo de tempo entre a morte de Mariátegui em 1930 e a época vivida por Quijano - curiosamente, nascido no ano da morte de Mariátegui - houve transformações profundas na realidade andina e latino-americana. Mariátegui abordou a questão indígena como problema nacional, a partir da tradição cultural e social peruana. Quijano, por seu turno, se interessou em um primeiro momento pelas novas dinâmicas que estavam em marcha no desenvolvimento desigual e combinado de seu país. Ele pertence a uma geração política e intelectual marcada pela emergência e consolidação das ciências sociais e das lutas sociais e políticas na América Latina. Ainda no Peru, ele vivencia a ascensão da esquerda revolucionária peruana, influenciada pela Revolução Cubana e pela ocupação de terras de Hugo Blanco, e, já no exílio no Chile, pelo ciclo político aberto em 1968, marcado pela ditadura militar de Juan Velasco Alvarado e as revoluções e conra-revoluções na América Latina. Ademais, Quijano testemunhou a inflexão histórica pela qual passou o mundo entre o final dos anos 1970 e os acontecimentos de 1989-1991, com o declínio da esquerda política, do marxismo intelectual, da crise de paradigmas das ciências sociais e das analises globalizantes.

Na contramão das separações binárias eurocêntricas, os aportes mariateguianos foram fundamentais para a construção da sociologia quijaneana, restituindo, assim, a unidade indissociável entre logos e mito como integrantes de um mesmo movimento de consciência e de reflexão. A utopia latino-americana como proposta de racionalidade alternativa assenta-se na rearticulação entre duas heranças histórico-culturais, a de origem andina e a da razão histórica. Dessa forma, a imaginação sociológica de Aníbal Quijano tem contribuído na produção de conhecimento criativo e transformador para a teoria social do século XXI.

\section{Notas}

1 Embora Quijano seja formado em História, seu campo de atuação e influência teórica concentrou-se nitidamente na Sociologia, uma das razões pelas quais se tornou professor na Faculdade de Ciências Sociais. A partir disso, chamamos a atenção para o fato de que os termos "cientista social" ou "ciências sociais" têm sentido amplo neste artigo. 
2 Quijano renunciará ao cargo de professor de Sociologia na UNMSM em 1995, após a intervenção militar do ditador Fujimori. Ele retornará à UNMSM em novembro de 2006, já como professor emérito.

3 Por meio de um convênio entre a USP e o Memorial da América Latina, Quijano tornou-se o primeiro titular da cátedra Simón Bolívar.

4 Para uma introdução das ideias de Quijano com informações biográficas relevantes, ver Clímaco (2014).

5 Todas as citações de excertos em língua estrangeira foram traduzidas por mim, a quem cabe todas as eventuais inconsistências.

6 Utilizado amplamente pelo grupo, o termo colonialidade foi estendido a outros âmbitos, além do conceito de poder (do saber, do ser). O grupo identifica-se também como projeto de "decolonização". Para uma análise sobre a trajetória intelectual do Grupo Modernidade/Colonialidade ou "programa de investigação de modernidade/ colonialidade", ver Ballestrin (2013) e Escobar (2003).

7 No Brasil, houve pouca ressonância de Mariátegui, como podemos constatar em Pericás (2010). As exceções foram Florestan Fernandes e Michael Löwy. Para maiores informações, ver Rubbo (2016) e Braga e Rubbo (2018).

8 Para uma síntese de sua produção sobre dependência, marginalidade e urbanização durante seu exílio no Chile (1966-1971), ver Cortéz (2017).

9 Para maiores detalhes acerca das apropriações de Quijano sobre Mariátegui nas décadas anteriores à de 1980, ver Rubbo (2018, p.148-63).

10 A expressão "racionalidade alternativa" surge, pela primeira vez, no livro Modernidad, identidad y utopia en America Latina. Ver Quijano (1988).

11 Para maiores informações dos atritos entre a Internacional Comunista e a delegação peruana, ver Flores Galindo (1994), que permanece o melhor trabalho sobre o tema, baseado em documentos e entrevistas.

12 Para uma análise sobre a relação entre Mariátegui e a questão negra, ver Forgues (1995, p.77-100).

\section{Referências}

ARGUEDAS, J. M. A raposa de cima e a raposa de baixo. Belo Horizonte: Editora UFMG, 2016.

BALLESTRIN, L. América Latina e o giro decolonial. Revista Brasileira de Ciência Politica, Brasília, n.11, p.89-117, 2013.

BEIGEL, F. Vida, muerte y resurrección de las “teorías de la dependencia”. In: VV.AA. Crítica y teoría en el pensamiento social latino-americano. Buenos Aires: Clacso, 2006.

BRAGA, R.; RUBBO, D. A. Dois mestres na periferia do capitalismo: Michael Löwy e Mariátegui. Cadernos CRH, Salvador, v.31, n.83, p.321-34, 2018.

ClímACO, D. A. Prólogo. In: QUIJANO, A. Cuestiones y horizontes: de la dependencia histórico-estructural a la colonialidad/descolonialidad del poder. Buenos Aires: Clacso, 2014. p.13-53. 
CORTÉZ, A. Aníbal Quijano: marginalidad y urbanización dependiente en América Latina. Polis, Revista Latinoamericana, Santiago, CEDER, n.46, 2017. Disponível em: <https://journals.openedition.org/polis/12348>. Acesso em: 20 abr. 2018.

ESCOBAR, A. Mundos y conocimiento de otro modo: el programa de investigación modernidad/colonialidad. Tabula Rasa, Bogota, n.1, p.58-86, 2003.

FERNÁNDEZ DÍAZ, O. Mariátegui o la experiencia del otro. Lima: Amauta, 1994.

FLORES GALINDO, A. La agonía de Mariátegui. La polémica con la Komintern. In: Obras completas. Lima: Fundación Andina-SUR/ Casa de Estudios del Socialismo, 1994. t.II.

José Carlos Mariátegui: marxista convicto y confeso [1988]. In: Obras completas. Lima: Fundación Andina-SUR/ Casa de Estudios del Socialismo, 2007. t.VI. FORGUES, R. El tiempo de la agonía (Entrevista com Aníbal Quijano). In: FORGUES, R. (Org.) Perú entre el desafío de la violencia y el sueño de lo posible. Lima: Minerva, 1993.

"La cuestión negra". In: La utopia realizable. Lima: Amauta, 1995.

GARCÍA MÁRQUEZ, G. A solidão da América Latina [1982]. In: . Eu não vim fazer um discurso. Rio de Janeiro: Record, 2011.

MARIÁtegUI, J. C. Defensa del marxismo, polemica revolucionaria. Lima: Amauta, 1959.

. Ideología y politica. Lima: Amauta, 1969.

- Peruanicemos al Perú. Lima: Amauta, 1970a.

El alma matinal y otras estaciones de hombre hoy. Lima: Amauta, 1970b.

MELIS, A. Prologo: en busca del marxismo de Mariátegui. In: SOBREVILLA, D. El marxismo de Mariátegui y su aplicación a los 7 ensayos. Lima: Universidad de Lima/ Fondo Editorial, 2012. p.17-20.

MIGNOLO, W. Prefacio. In: PALERMO, Z.; QUINTERO, P. (Org.) Aníbal Quijano: textos de fundación. Buenos Aires: Del Signo, 2014. p.5-7.

Colonialidade: o lado mais escuro da modernidade. Revista Brasileira de Ciências Sociais, v.21, n.94, 2017. Disponível em: <http://www.scielo.br/pdf/rbcsoc/ v32n94/0102-6909-rbcsoc-3294022017.pdf>. Acesso em: $1^{\circ}$ jul. 2017.

PERICÁS, L. B. José Carlos Mariátegui e o Brasil. Estudos Avançados, São Paulo, v.68, n.24, p.335-61, 2010.

QUIJANO, A. Reencuentro y debate: una introducción a Mariátegui [1979]. Lima: Mosca Azul/CEIS, 1981.

. Modernidad, identidad y utopía en América Latina. Lima: Ediciones Sociedad y Política, 1988.

La nuova heterogeneidad estructural de America Latina. Hueso Humero, Lima, n.26, 1990, p.8-23.

- Prólogo. In: MARIÁTEGUI, J. C. Textos basicos de José Carlos Mariátegui (Seleção, prólogo e notas introdutórias de Aníbal Quijano). Lima-México: Fondo de Cultura Económica, 1991. p.VII-XVI. 
QUIJANO, A. Colonialidad y modernidad/racionalidade. Perú Indígena, Lima, v.12, n.29, p.11-20, 1992.

. Raza, etnia y nación: cuestiones abiertas. In: VV.AA. Jose Carlos Mariategui y Europa: el outro descubrimiento. Lima: Amauta, 1993. p.167-89.

El sueño dogmático. In: FERNÁNDEZ DÍAZ, O. Mariátegui o la experiencia del otro. Lima: Amauta, 1994. p.XI-XV.

El marxismo en Mariátegui: una propuesta de racionalidade alternativa. In: VV.AA. El marxismo de Mariátegui. Seminário do V Congreso Nacional de Filosofía. Lima: Amauta, 1995. p.39-47.

Colonialidad del poder y clasificación social. Journal of World-Systems, v.11, n.2, 2000, p.342-86.

. Treinta años después: otro reencuentro. Notas para otro debate. In: MARIÁTEGUI, J. C. Siete ensayos de interpretación de la realidad peruana. (Notas, cronologia e bibliografia de Elizabeth Garrels). Caracas: Biblioteca Ayacucho, 2007. p.CXIII-CXXIX.

La tensión del pensamiento latino americano [1986]. In: Cuestiones y horizontes: de la dependencia histórico-estructural a la colonialidad/descolonialidad del poder. Buenos Aires: Clacso, 2014a. p.697-704.

. Arguedas: la sonora banda de la sociedad [1984]. In: Cuestiones y horizontes: de la dependencia histórico-estructural a la colonialidad/descolonialidad del poder. Buenos Aires: Clacso, 2014b. p.691-6.

QUIJANO, A.; GUTIÉRREZ, G.; LÓPEZ, S. Mariátegui contra la expropiación de la utopia. Cuestion De Estado, Lima, ano 2, n.8-9, p.37-51, 1994.

RUBBO, D. A. "Nosso irmão mais velho": Florestan Fernandes leitor de Mariátegui. Lua Nova, São Paulo, n.99, 2016, p.70-105.

O labirinto periférico: José Carlos Mariátegui e a sociologia crítica latino-americana. São Paulo, 2018. Tese (Doutorado em Sociologia) - Faculdade de Filosofia, Letras e Ciências Humanas, Universidade de São Paulo. São Paulo, 2018.

SCORZA, M. Prólogo. MARIÁTEGUI, J. C. Ensayos escogidos de José Carlos Mariátegui. Lima: Primer Festival del Libro Peruano, 1956. (Seleção de Aníbal Quijano).

SEGATO, R. L. La perspectiva de colonialidad del poder. In: PALERMO, Z.; QUINTERO, P. (Org.) Aníbal Quijano: textos de fundación. Buenos Aires: Del Signo, 2014. p.9-39.

SOBREVILLA, D. El marxismo de Mariátegui y su aplicación a los 7 ensayos. Lima: Universidad de Lima/Fondo Editorial, 2012.

VILLENA FIENGO, S. Palabras en ocasión de la entrega del doctorado Honoris Causa a Aníbal Quijano Obregón. In: Anuario de Estudios Centroamericanos, Universidad de Costa Rica, n.42, p.465-481, 2016.

RESUMO - Este artigo tem como objetivo discutir a perspectiva "decolonial" de Aníbal Quijano (1930-2018) e seus usos a partir de José Carlos Mariátegui. Em primeiro lugar, relacionamos o contexto histórico latino-americano desde a década de 1980 ao 
esforço de interpretação de Mariátegui por Aníbal Quijano, balizado, sobretudo, pela formulação de uma teoria fundacional (filosófica, epistemológica, ética e política) sobre a especificidade da América Latina. Na sequência, Quijano redescobre, assim, certo Mariátegui associado à renovação crítica da teoria social latino-americana. Através de múltiplos mecanismos de difusão, ele estabelece uma reconhecida caracterização filosófica e epistemológica do arsenal mariateguiano, visto como bastião da crítica eurocêntrica ("racionalidade alternativa"), para legitimá-lo como referência fundamental da teoria da “colonialidade do poder".

PALAVRAS-CHAVE: Aníbal Quijano, José Carlos Mariátegui, Colonialidade do poder, Marxismo na América Latina, Racionalidade alternativa, Crítica do eurocentrismo.

ABSTRACT - This article aims to discuss the "decolonial” perspective of Aníbal Quijano (1930-2018) and its uses after José Carlos Mariátegui. Firstly, we relate the Latin American historical context since the 1980s to Marítegui's interpretation of Aníbal Quijano's work, based mainly on the formulation of a foundational theory (philosophical, epistemological, ethical and political) on the specificity of Latin America. Quijano then rediscovers a certain Mariátegui associated with the critical renovation of Latin American social theory. Through multiple mechanisms of dissemination, he establishes an well-acknowledged philosophical and epistemological characterization of Mariátegui's arsenal, seen as the bastion of Eurocentric criticism ("alternative rationality"), in order to legitimize it as a fundamental reference of the "coloniality of power" theory.

KErWORDs: Aníbal Quijano, José Carlos Mariátegui, Coloniality of power, Marxism in Latin America, Alternative rationality, Critique of eurocentrism.

Deni Alfaro Rubbo é doutor em Sociologia pela Universidade de São Paulo (USP). É autor de Párias da terra: o MST e a mundialização da luta camponesa (Alameda; Fapesp, 2016). @-deni_out27@uol.com.br

Recebido em 26.7.2018 e aceito em 23.8.2018.

I Faculdade de Filosofia, Letras e Ciências Humanas, Universidade de São Paulo, São Paulo, São Paulo, Brasil. 
